\title{
RECONHECIMENTO DOS ATIVOS INTANGÍVEIS NAS COMBINAÇÕES DE NEGÓCIOS: UMA ANÁLISE NAS CARACTERÍSTICAS DAS COMPANHIAS DE CAPITAL ABERTO BRASILEIRAS NO PERÍODO ENTRE 2012 E 2014
}

\author{
RECOGNITION OF INTANGIBLE ASSETS IN BUSINESS COMBINATION: AN ANALYSIS \\ ON THE CHARACTERISTICS OF CAPITAL COMPANIES IN BRAZIL OPEN PERIOD 2012 \\ AND 2014
}

\author{
Juliana Cordeiro Campodonio Eloy ${ }^{1}$ \\ Universidade Federal de Santa Catarina \\ juh.eloy@gmail.com
}

\author{
Maíra Melo de Souza \\ Universidade Federal de Santa Catarina \\ mairameloufsc@gmail.com
}

\begin{abstract}
RESUMO
Este estudo tem por objetivo identificar as características dos ativos intangíveis reconhecidos nas combinações de negócios e sua relação com as características das companhias de capital aberto brasileiras no período entre 2012 e 2014. Para alcançar o objetivo foi elaborada uma lista de verificação com base no CPC 15 (R1) elencando as características dos ativos intangíveis adquiridos e também foram analisadas as seguintes características das companhias: proporção do goodwill em relação à contraprestação, o índice de rentabilidade, nível de governança corporativa e o setor de atuação. Quanto aos resultados, dos setores de atuação, o setor de consumo cíclico foi o que apresentou o maior número de companhias dentre as que realizaram combinações de negócios no período analisado. Quanto ao nível de governança corporativa, a maioria das companhias classificadas em algum nível diferenciado reconheceram goodwill, enquanto que mais da metade das companhias sem classificação diferenciada de governança corporativa não reconheceram goodwill.
\end{abstract}

Palavras-Chave: Ativos intangíveis identificáveis. Goodwill. Combinações de negócios.

\begin{abstract}
This study aims to identify the characteristics of intangible assets recognized in business combinations and their relationship to the characteristics of Brazilian public companies in the period between 2012 and 2014. To achieve the objective of the research was drawn up a checklist based on CPC 15 (R1) listing the characteristics of acquired intangible assets and were also analyzed the following companies: proportion of goodwill in relation to the consideration, the profitability index, level of corporate governance and market sector. Regarding the results, of the sectors of activity of the companies, the cyclical consumption sector was the one that presented the largest number of companies that performed business combinations in the analyzed period. As for governance, most companies rated at some level of governance recognized goodwill, while more than half of non-governance companies did not recognize goodwill.
\end{abstract}

Key-words: Identifiable intangible assets. Goodwill. Business combinations.

\footnotetext{
${ }^{1}$ Juliana Cordeiro Campodonio Eloy - UFSC CEP: 89216-400, Joinville-Santa Catarina-Brasil. Rua Colon, $\mathrm{n}^{\circ}$ 100, Bairro Gória,
} 


\section{INTRODUÇÃO}

Nos últimos anos, a maioria das entidades cotadas nas bolsas de valores do mundo vem apresentando uma acentuada diferença entre o seu valor econômico e o seu valor contábil. Essa diferença está vinculada à relevância que os ativos intangíveis vêm exercendo em relação aos ativos tangíveis na composição patrimonial das entidades (SCHMIDT; SANTOS, 2009).

Nesse contexto estão inseridas as combinações de negócios, que são operações de reorganização societária mediante processos de aquisições, incorporações, fusões ou cisões, realizadas entre empresas ocorrendo transferência de controle de um ou mais negócios (NEVES, 2011). Essas operações contribuem de forma mais rápida para o crescimento de uma empresa, o ingresso em mercados ainda não explorados, ou ainda favorecer o lucro de alguns participantes sobre outros envolvidos (CAMARGOS; BARBOSA, 2003).

Em algumas combinações de negócios o valor da contraprestação negociado entre as entidades envolvidas é superior ao valor justo dos ativos líquidos adquiridos. Essa diferença entre os valores corresponde aos ativos intangíveis reconhecidos nas combinações, os quais podem ser identificáveis ou não. O ativo intangível é conceituado pelo Pronunciamento Técnico CPC 04 (R1, 2010, p.6) como "um ativo não monetário identificável e sem substância física". Como exemplos de ativos intangíveis têm-se as marcas, patentes, gastos com propaganda, reputação, imagem, etc.

Conforme mencionado, a definição de ativo intangível exige que ele seja identificável, e para atender a este critério o ativo deve ser separável, ou seja, que possa ser negociado separadamente da entidade, ou deve resultar de direitos contratuais ou outros direitos legais. (CPC 15, R1, 2011).

$\mathrm{Na}$ hipótese de o ativo adquirido não atender aos itens referentes à definição estabelecidos pela norma, este passa a fazer parte do goodwill, o qual é conceituado pelo CPC 15 (R1, 2011, p.21) como "um ativo que representa benefícios econômicos futuros resultantes dos ativos adquiridos em combinação de negócios, os quais não são individualmente identificados e separadamente reconhecidos”. Desta maneira, o goodwill é um intangível não identificável.

O goodwill adquirido nas combinações de negócios é tratado pela contabilidade como um resíduo, representando a diferença entre o valor líquido dos ativos e passivos avaliados a valor justo e o valor conferido ao negócio. Os ativos intangíveis não identificados, um sobrepreço e uma expectativa de rentabilidade futura são itens que estão inclusos ao valor do goodwill. (NAKAYAMA; SALOTTI, 2014). 
Nesse cenário surge a preocupação com a forma de como é realizado o reconhecimento dos ativos intangíveis adquiridos nas combinações de negócios, se há preocupação por parte das companhias na forma como são tratadas as informações contábeis desses ativos, e se os valores correspondem à realidade dos ativos intangíveis adquiridos.

Diante do exposto, esse estudo apresenta o seguinte problema de pesquisa: Quais as características dos ativos intangíveis reconhecidos nas combinações de negócios das companhias de capital aberto brasileiras no período entre 2012 e 2014 ?

Tendo em vista estes aspectos, o presente estudo tem por objetivo geral identificar as características dos ativos intangíveis reconhecidos nas combinações de negócios e sua relação com as características das companhias de capital aberto brasileiras no período entre 2012 e 2014.

O estudo das características dos ativos intangíveis adquiridos é elementar para a contabilidade e áreas afins, pois apresentar as características dos ativos intangíveis, considerando a dificuldade existente no reconhecimento e mensuração desses ativos, é um desafio para as empresas envolvidas nas combinações de negócios e demais usuários da informação, visto que se espera que as entidades representem fidedignamente as informações referentes aos ativos intangíveis. Além disso, o trabalho contribui como base de discussão para futuros estudos referentes às características dos ativos intangíveis identificáveis e ao goodwill adquiridos nas combinações de negócios.

\section{FUNDAMENTAÇÃO TEÓRICA}

\subsection{Reconhecimento dos ativos intangíveis nas combinações de negócios}

Nos termos do CPC 15 (R1, 2011) as combinações de negócios são operações em que há transferência de controle de um ou mais negócios, independente da forma jurídica da operação, sendo a contabilização pelo método de aquisição. A mensuração dos ativos identificáveis adquiridos e dos passivos assumidos deve ser realizada pelos valores justos da data de aquisição.

Conforme o CPC 15 (R1, 2011), o método de aquisição exige que, em uma combinação de negócios, o adquirente do controle deve ser identificado. Além da identificação do controlador, o referido Pronunciamento CPC 15 (R1, 2011) exige que a data de aquisição do controle seja informada, e ainda deve ser feito o reconhecimento e mensuração dos ativos identificáveis e passivos líquidos assumidos, a participação dos não controladores na adquirida e o ágio por expectativa de rentabilidade futura (goodwill). 
Nesse contexto, nas operações de combinações de negócios existe uma parcela do valor atribuído ao negócio pago pela entidade adquirente que geralmente excede os valores justos dos ativos líquidos adquiridos e dos passivos assumidos. Esse valor é representado pelos ativos intangíveis adquiridos reconhecidos nas operações, os quais podem ser identificáveis ou não identificáveis.

De acordo com o CPC 04 (R1, 2010, p.6), ativo intangível é definido como "um ativo não monetário identificável e sem substância física”. Para atender a definição de ativo intangível, o recurso deve ser identificável (separável ou resultar de direitos contratuais), controlado pela empresa e ser capaz de gerar benefícios econômicos futuros.

No que tange a mensuração, alguns ativos intangíveis sofrem amortização da mesma forma que os ativos tangíveis são depreciados e outros possuem vida útil indefinida, não sofrendo amortização periódica e sendo testados por impairment a cada ano. A vida útil empregada deve ser sua duração econômica estimada. (MARQUES; SANTOS; GOUVEIA, 2011).

Ressalta-se que existe também o goodwill que é considerado um intangível, apesar de não ser identificável, contudo, este ativo é tratado de maneira específica pelo CPC 15 (R1, 2011), não estando no escopo do pronunciamento CPC 04 (R1, 2010).

Concernente ao reconhecimento e à caracterização, Hendriksen e Van Breda (2009) aduzem que os ativos intangíveis constituem elementos incorpóreos, não deixando de ser considerados ativos simplesmente por não apresentarem substância física. Sendo assim, seu reconhecimento deve ser realizado em consonância com as normas e procedimentos estabelecidos para todos os ativos. Souza (2015) considera, com base no Pronunciamento CPC 04 (R1) que rege os ativos intangíveis, que:

A definição de ativo intangível disposta pelo CPC 04 R1 exige que ele seja identificável, o que exclui o ágio derivado da expectativa de rentabilidade futura (goodwill) do seu escopo, visto que os ativos que podem separadamente ser identificados são reconhecidos separadamente do goodwill em uma combinação de negócios, já aqueles que não podem ser separados e mensurados confiavelmente integram o valor do goodwill gerado na combinação de negócios. (SOUZA, 2015).

Desse modo, os ativos intangíveis que não atendem a definição estabelecida pelo CPC 04 (R1), no qual o ativo intangível deve ser identificável, devem ser integrados ao valor do goodwill (ágio gerado na expectativa de rentabilidade futura) gerado na combinação de negócios.

O CPC 15 (R1, 2011, p.21) conceitua o goodwill como "um ativo que representa benefícios econômicos futuros resultantes dos ativos adquiridos em combinação de negócios, os quais não são individualmente identificados e separadamente reconhecidos”. Para Schmidt 
e Santos (2009) o goodwill é um excesso do preço pago na aquisição de um negócio acima ou abaixo do valor avaliado de seus ativos líquidos.

Souza (2015) explica que quando o preço pago pela controladora for maior que a porcentagem do patrimônio líquido (PL) contábil da adquirida, a diferença total constituirá um ágio que será divido em três itens, sendo eles: i) a diferença entre o valor justo e o valor contábil dos ativos líquidos da adquirida, ii) os intangíveis identificáveis, e iii) o goodwill.

Dessa maneira, o goodwill é um ativo com alto grau de subjetividade, sendo considerado pelos usuários da informação contábil como um dos ativos mais complexos na sua definição, além da forma de mensuração e reconhecimento. (SCHMIDT, SANTOS, 2009).

Vale salientar que o CPC $15(\mathrm{R} 1,2011)$ permite que as companhias adquirentes realizem ajustes nos valores reconhecidos na combinação de negócios durante o período de mensuração, que não poderá exceder um ano após a data de aquisição. Os ajustes que forem realizados nesse período terão o goodwill como contrapartida.

\subsection{Evidenciação dos ativos intangíveis nas combinações de negócios}

Conforme o CPC 04 (R1, 2010) as entidades devem divulgar informações para cada classe de ativos intangíveis, sendo necessário realizar a distinção entre os ativos intangíveis gerados internamente e os demais ativos. Uma classe de ativos intangíveis, de acordo com o CPC 04 (R1, p.30, 2010) "é um grupo de ativos de natureza e com utilização similar nas atividades da entidade". As informações que devem ser divulgadas são:

(a) com vida útil indefinida ou definida e, se definida, os prazos de vida útil ou as taxas de amortização utilizadas; (b) os métodos de amortização utilizados para ativos intangíveis com vida útil definida; (c) o valor contábil bruto e eventual amortização acumulada (mais as perdas acumuladas no valor recuperável) no início e no final do período; (d) a rubrica da demonstração do resultado em que qualquer amortização de ativo intangível for incluída; (e) a conciliação do valor contábil no início e no final do período. (CPC 04, R1, p.29, 2010).

Com relação aos ativos intangíveis com vida útil indefinida, a entidade deve divulgar os fatores que contribuíram para a definição de vida útil indefinida do ativo. Também deve ser divulgado o valor contábil, uma descrição, além do prazo de amortização remanescente de ativos intangíveis individuais considerados relevantes para os demonstrativos financeiros da entidade. (CPC 04, R1, 2010).

Referente à evidenciação do goodwill, Nakayama e Salotti (2014) realizaram um estudo sobre o nível de divulgação das informações relativas às combinações de negócios. Na pesquisa foi identificado que, com relação ao goodwill reconhecido em relação ao valor da contraprestação transferida, em grande parte das operações o goodwill foi apurado pela diferença entre o valor pago e o valor contábil, sendo essa diferença justificada como 
expectativa de rentabilidade futura. Essa apuração denota que algumas companhias ainda confundem os conceitos de ágio e goodwill.

Referente ao nível de divulgação das combinações de negócios, Souza (2015) realizou um estudo sobre o value relevance do nível de disclosure das combinações de negócios e do goodwill reconhecido nas empresas brasileiras. Os resultados do estudo foram que o nível médio de evidenciação das combinações de negócios no Brasil é baixo, sendo as informações fornecidas insuficientes para conferir uma percepção adequada dos métodos utilizados e dos ativos adquiridos nas combinações de negócios.

Dessa forma, Souza (2015) considera que é necessário que os órgãos normatizadores revisem a norma que trata das combinações de negócios, para que possam ser esclarecidos aspectos inerentes ao reconhecimento dos ativos intangíveis e do goodwill e também a adição de itens de divulgação referentes ao valor justo e a necessidade da divulgação dos valores contábeis dos ativos adquiridos.

É possível perceber que, a evidenciação das informações referentes aos ativos intangíveis reconhecidos nas combinações de negócios não apresenta a transparência necessária para atender de forma eficiente aos usuários dessas informações, considerando que a divulgação é um fator que apresenta relevância significativa na área contábil, pois conforme Souza (2015) as empresas que apresentam bons níveis de divulgação nas demonstrações contábeis contribuem com a transparência de suas informações e reduzem a assimetria informacional entre os usuários da informação. O próximo tópico contempla os estudos anteriores semelhantes a esta pesquisa.

\subsection{Estudos semelhantes}

Para seleção das pesquisas semelhantes foi realizado um levantamento nas bases de dados Scientific Periodicals Electronic Library (SPELL) e da Coordenação de Aperfeiçoamento de Pessoal de Nível Superior (CAPES), nos Congressos de Contabilidade da Universidade Federal de Santa Catarina, Congresso de Contabilidade da Universidade de São Paulo e Associação Nacional de Programas de Pós-graduação em Ciências Contábeis (ANPCONT), todos na área de contabilidade.

Foram fixadas as seguintes palavras-chave para o levantamento de trabalhos: Intangível, Intangível Identificável, Goodwill e Combinações de Negócios. O Quadro 1 apresenta os estudos semelhantes nacionais e internacionais identificados de acordo com os parâmetros de busca especificados. 
Quadro 1: Pesquisas semelhantes sobre ativos intangíveis e combinações de negócios

\begin{tabular}{|c|c|c|}
\hline Autores & Objetivo e período analisado & Resultados \\
\hline $\begin{array}{l}\text { Henning, } \\
\text { Lewis e } \\
\text { Shaw } \\
(2000)\end{array}$ & $\begin{array}{l}\text { O objetivo desta pesquisa foi elucidar } \\
\text { quais são os componentes que existem } \\
\text { dentro do goodwill e avaliar sua } \\
\text { relevância. O período analisado foi de } \\
1990 \text { até } 1994 \text {. }\end{array}$ & $\begin{array}{l}\text { Os autores verificaram que o item predominante } \\
\text { existente no goodwill é a sinergia decorrente da } \\
\text { combinação de negócios. O estudo também constatou } \\
\text { que o goodwill relativo a sinergia se mostrou relevante } \\
\text { para os investidores. }\end{array}$ \\
\hline $\begin{array}{l}\text { Watanabe } \\
\text { et al. } \\
(2006)\end{array}$ & $\begin{array}{l}\text { Analisar as operações de combinações de } \\
\text { negócios de acordo com as normas } \\
\text { brasileiras e norte-americanas em uma } \\
\text { empresa do ramo de papel e celulose, no } \\
\text { período de } 2003 \text {. }\end{array}$ & $\begin{array}{l}\text { Os resultados mostraram que o nível de divulgação e } \\
\text { evidenciação da demonstração financeira norte- } \\
\text { americana é superior ao brasileiro, pois oferece aos } \\
\text { usuários da informação maiores detalhes sobre as } \\
\text { operações. }\end{array}$ \\
\hline $\begin{array}{l}\text { Dahmash, } \\
\text { Durand e } \\
\text { Watson } \\
(2009)\end{array}$ & $\begin{array}{l}\text { O objetivo da pesquisa foi verificar a } \\
\text { relevância e a confiabilidade da } \\
\text { divulgação do goodwill e dos ativos } \\
\text { intangíveis identificáveis nas empresas } \\
\text { australianas. O período analisado foi entre } \\
1994 \text { até } 2003 \text {. }\end{array}$ & $\begin{array}{l}\text { Os autores puderam concluir que as informações } \\
\text { relativas ao goodwill são divulgadas de uma maneira } \\
\text { mais conservadora por parte das companhias } \\
\text { analisadas, enquanto as informações sobre os } \\
\text { intangíveis identificáveis são divulgadas de uma } \\
\text { maneira mais agressiva. Fato que os autores } \\
\text { ressaltaram que o goodwill apesar de relevante tende } \\
\text { a ser divulgado com maior precaução por parte das } \\
\text { companhias. }\end{array}$ \\
\hline $\begin{array}{l}\text { Barros e } \\
\text { Rodrigues } \\
(2014)\end{array}$ & $\begin{array}{l}\text { Analisar as aquisições de participações } \\
\text { realizadas por sessenta empresas no } \\
\text { exercício de } 2011 \text {. }\end{array}$ & $\begin{array}{l}\text { Os resultados da analise demonstraram que muitas } \\
\text { empresas não estão divulgando as informações } \\
\text { conforme as determinações constantes das normas } \\
\text { internacionais de contabilidade. }\end{array}$ \\
\hline $\begin{array}{l}\text { Marques } \\
\text { et } \quad \text { al. } \\
(2011)\end{array}$ & \begin{tabular}{|l} 
Analisar dos ativos intangíveis divulgados \\
nas demonstrações contábeis de 2008 \\
pelas companhias vencedoras do $13^{\circ}$ \\
Prêmio ANEFAC-FIPECAFI-SERASA \\
EXPERIAN - Troféu Transparência 2009.
\end{tabular} & $\begin{array}{l}\text { A pesquisa concluiu que a maioria das empresas } \\
\text { analisadas está cumprindo as normas pertinentes à } \\
\text { divulgação desses ativos. A classe dos ativos } \\
\text { intangíveis presentes nas demonstrações contábeis } \\
\text { está aderente à normatização contábil vigente. }\end{array}$ \\
\hline $\begin{array}{l}\text { Chaves e } \\
\text { Junior } \\
(2013)\end{array}$ & $\begin{array}{l}\text { Verificar se existe relação entre os } \\
\text { retornos dos ativos intangíveis publicados } \\
\text { em balanço patrimonial e o retorno do } \\
\text { valor de mercado das empresas da } \\
\text { Bovespa nos últimos cinco períodos } \\
\text { trimestrais de dados publicados. }\end{array}$ & $\begin{array}{l}\text { O estudo concluiu que os ativos intangíveis } \\
\text { organizacionais não refletem uma amortização ou } \\
\text { criação de valores de mercados respectivos. Também } \\
\text { foi constatado que o valor de mercado gerado pelas } \\
\text { expectativas dos investidores não sofre influência do } \\
\text { somatório de valores incorpóreos organizacionais. }\end{array}$ \\
\hline $\begin{array}{l}\text { Nakayama } \\
\text { e Salotti } \\
(2014)\end{array}$ & $\begin{array}{llllr}\text { Identificar } & \text { quais os } & \text { fatores } & \text { que } \\
\text { influenciam a decisão da empresa } & \text { em } \\
\text { divulgar um maior ou menor nível } & \text { de } \\
\text { informação sobre as operações } & \text { de } \\
\text { combinação de negócios ocorridas } & \text { em } \\
2010 . & \end{array}$ & $\begin{array}{l}\text { Os resultados indicam que o porte da empresa de } \\
\text { auditoria influencia o nível de divulgação das } \\
\text { informações sobre a combinação de negócios. }\end{array}$ \\
\hline $\begin{array}{l}\text { Mantovani } \\
\text { e Santos } \\
(2014)\end{array}$ & $\begin{array}{l}\text { Apresentar quais os impactos dos ativos } \\
\text { intangíveis no patrimônio das entidades } \\
\text { brasileiras listadas na BM\&FBOVESPA, } \\
\text { com base no período de } 2012 \text {. }\end{array}$ & $\begin{array}{l}\text { Os resultados demonstraram que em algumas } \\
\text { companhias os intangíveis chegam a representar quase } \\
\text { a totalidade dos ativos da empresa. Eles acreditam que } \\
\text { os ativos intangíveis são bens que podem influenciar } \\
\text { diretamente nas operações de aquisição e fusão entre } \\
\text { empresas ou oferta de ações. }\end{array}$ \\
\hline
\end{tabular}

Fonte: Elaborado pelos autores.

A partir dos estudos selecionados, pode-se inferir que o nível de divulgação das informações de combinações de negócios passou a ser maior com a convergência das normas internacionais, visto que no estudo realizado anteriormente à convergência das normas, foi observado que o nível de divulgação e evidenciação das companhias brasileiras era inferior ao nível das companhias norte-americanas. 
Apesar da convergência das normas internacionais, ainda existem muitas companhias que não estão divulgando as informações conforme as determinações constantes das normas internacionais de contabilidade, o que pode acarretar em distorções das informações contábeis.

Outro aspecto observado foi que o porte da empresa de auditoria é um fator que se mostrou influente quanto ao nível de evidenciação das informações referentes às combinações de negócios, enquanto que o porte da empresa adquirente não apresenta relação direta quanto ao grau de abertura das informações.

\section{METODOLOGIA DA PESQUISA}

\subsection{Técnicas e instrumento de pesquisa}

Nesta pesquisa, para alcançar aos objetivos da pesquisa delimitados, inicialmente foi elaborada uma Lista de Verificação com base nos parâmetros estabelecidos pelo CPC 15 (R1). O Quadro 2 apresenta os itens que integram a lista de verificação utilizada como parâmetro para coleta dos dados nas notas explicativas das companhias componentes da amostra analisada:

Quadro 2 - Lista de verificação realizada com base no CPC 15 (R1)

\begin{tabular}{|l|}
\hline 1) O tipo de combinação de negócios realizada. \\
\hline 2) A informação se a contraprestação foi em dinheiro, açães ou assunção de passivos. \\
\hline 3) Menção ao período de mensuração. \\
\hline 4) Informação sobre os ativos que sofreram alteração no período de mensuração. \\
\hline 5) Informação sobre o valor total dos ativos que sofreram alteração no período de mensuração. \\
\hline 6) Informação sobre o valor individual dos ativos que sofreram alteração. \\
\hline 7) Especificação de quais passivos sofreram alteração. \\
\hline 8) Informação sobre o valor total dos passivos que sofreram alteração. \\
\hline 9) Informação sobre o valor individual dos passivos que sofreram alteração. \\
\hline 10) Valor da contraprestação (em Mil). \\
\hline 12) Data de aquisição. \\
\hline 13) Valor total dos intangíveis identificáveis. \\
\hline 14) Valor individual dos intangíveis identificáveis. \\
\hline 15) Nome de cada intangível identificável reconhecido. \\
\hline 16) Vida útil estimada de cada intangível identificável. \\
\hline 17) Valor total do goodwill. \\
\hline 18) Fatores que integram o goodwill reconhecido. \\
\hline 19) Denominação utilizada para se referir ao goodwill. \\
\hline
\end{tabular}
Fonte: Elaborado pelos autores com base no CPC 15 (R1).

Conforme demonstra o Quadro 2, foram consideradas informações pertinentes às combinações de negócios abrangendo a identificação da empresa adquirente, a data de aquisição, o período de mensuração e as possíveis alterações realizadas nos ativos e passivos assumidos, os aspectos dos ativos intangíveis identificáveis reconhecidos e os elementos referentes ao goodwill.

\subsection{Procedimentos de pesquisa}


De posse dos dados coletados nas notas explicativas, a partir da lista de verificação, das companhias componentes da amostra, realizou-se o levantamento das informações relativas aos ativos intangíveis reconhecidos nos anos de 2012, 2013 e 2014.

Adicionalmente, para análise dos itens 3 até 9 da lista de verificação, realizou-se a análise das informações pertinentes às notas explicativas relativas ao período de mensuração referente ao ano posterior a cada ano analisado, dessa maneira: para 2012 observou-se 2013, para 2013 observou-se 2014 e para 2014 analisou-se 2015. Esse procedimento foi realizado visando identificar se as companhias alteraram os valores reconhecidos como intangíveis identificáveis e goodwill no período em que o CPC 15 (R1) permite essas alterações.

Como complemento aos aspectos analisados na pesquisa, foram selecionadas, com base na literatura, algumas características referentes às companhias, para relacionar com as informações que compõem a Lista de Verificação. O conjunto das características levantadas é composto pela proporção do goodwill em relação à contraprestação, o índice de rentabilidade, se negocia American Depositary Receipt (ADRs) na New York Stock Exchange (NYSE), nível de governança corporativa e o setor de atuação. Nos tópicos seguintes estão apresentadas individualmente cada característica analisada nesta pesquisa.

\subsubsection{Proporção do Goodwill em relação à contraprestação}

No estudo realizado por Nakayama e Salotti (2014) foi identificado que um maior reconhecimento de goodwill em relação à contraprestação leva as empresas a divulgarem um menor nível de informação. Souza (2015) analisou a proporção do goodwill em relação à contraprestação das combinações de negócios realizadas entre os períodos de 2010 a 2013, e foi apurado que a média da proporção foi superior em $50 \%$ nos anos analisados.

O cálculo da proporção do goodwill em relação ao valor da transação é realizado por meio da razão do goodwill pela contraprestação da combinação de negócios (NAKAYAMA; SALOTTI, 2014). Nesta pesquisa, os dados relativos a esta característica foram obtidos nas notas explicativas das companhias pertencentes à amostra.

\subsection{2 Índice de Rentabilidade}

Os índices de rentabilidade analisam os aspectos econômicos das empresas. O índice de rentabilidade do ativo, em inglês Return on Investment, mensura o retorno de um investimento realizado em períodos nos quais ele será amortizado para então começar a gerar lucros. (MARION, 2013). 
O cálculo do índice de rentabilidade do ativo é realizado por meio da razão entre o resultado líquido do período em relação ao ativo total da companhia. Os índices de rentabilidade da amostra utilizados na pesquisa foram extraídos da base de dados ECONOMATICA.

\subsubsection{Negocia ADRs na New York Stock Exchange (NYSE)}

A emissão de American Depositary Receipts (ADRs) no mercado norte-americano pelas companhias brasileiras exige que elas apresentem um maior grau de abertura das informações do que o exigido pela legislação brasileira, devido às regras americanas. (LANZANA, 2004). Dessa maneira, nesta pesquisa considerou-se importante a análise desta característica. Os dados das companhias brasileiras que emitem ADRs no mercado norte-americano foram obtidos no site da NYSE.

\subsubsection{Nível de Governança Corporativa}

A governança corporativa é um conjunto de mecanismos que visa reduzir os conflitos de agência, criando condições novas favoráveis ao desempenho das companhias e protegendo todas as partes relacionadas. Um dos determinantes da governança corporativa é a transparência, visto que ela contribui para um melhor nível de evidenciação contábil, promovendo uma maior clareza na divulgação das informações financeiras (JORDÃO et al. 2009). Os dados foram obtidos no site da Bolsa de Mercadorias e Futuros e Bolsa de Valores de São Paulo (BM\&FBOVESPA).

\subsubsection{Setor de Atuação}

Nesta pesquisa, considerou-se relevante realizar a análise dos resultados por setor. A classificação setorial das companhias, analisadas nesta pesquisa, foi obtida conforme as informações publicadas no site da BM\&FBOVESPA.

\subsection{População e amostra de pesquisa}

Amostra da pesquisa é composta pelas companhias de capital aberto brasileiras que realizaram combinações de negócios no período entre 2012 a 2014. A listagem das companhias que realizaram combinações de negócios nos períodos de 2012 e 2013 foi extraída do estudo realizado por Souza (2015).

Para obtenção da amostra referente ao período de 2014 foi realizado um levantamento das notas explicativas de todas as companhias abertas listadas na BM\&FBOVESPA para 
verificar quais realizaram combinações de negócios no exercício de 2014. Nas notas explicativas foi feita a busca pelas palavras: Combinação, Combinações, Fusão, Incorporação, Aquisição, Cisão e Contraprestação. Foram identificadas 29 companhias que realizaram combinações de negócios no ano de 2014.

O Quadro 3 apresenta o número de companhias e a quantidade de combinações que foram realizadas em cada ano, considerando que a pesquisa analisou as características dos ativos intangíveis evidenciados em cada combinação de negócios:

Quadro 3: Composição da amostra da pesquisa

\begin{tabular}{|l|c|c|}
\hline Ano & Quantidade de companhias & Quantidade de combinações evidenciadas \\
\hline 2012 & 28 & 53 \\
\hline 2013 & 16 & 34 \\
\hline 2014 & 29 & 43 \\
\hline Total & 57 & 130 \\
\hline
\end{tabular}

Fonte: Elaborado pelos autores.

Dessa maneira, a amostra de pesquisa foi composta por 28 companhias em 2012, 14 em 2013 e 29 em 2014, perfazendo um total de 57 companhias e 130 combinações de negócios analisadas. O número total das companhias é inferior ao somatório das combinações de negócios realizadas nos três períodos pelo fato de algumas companhias terem realizado várias combinações de negócios em um mesmo ano. Dessa maneira, a análise dos dados nesta pesquisa foi realizada por combinações de negócios realizadas, perfazendo um total de 130 casos de combinações de negócios analisados.

\section{ANÁLISE DOS RESULTADOS}

A Tabela 1 demonstra o reconhecimento dos ativos intangíveis adquiridos nas combinações de negócios e o percentual em relação ao total de combinações de negócios ocorridas nos três períodos analisados (130 combinações de negócios analisadas).

Tabela 1: Ativos intangíveis adquiridos X combinações de negócios analisadas

\begin{tabular}{l|c|c|c|c}
\hline \multirow{2}{*}{$\begin{array}{l}\text { Reconhecimento dos ativos intangíveis } \\
\text { adquiridos nas combinações de negócios }\end{array}$} & 2012 & 2013 & 2014 & $\begin{array}{l}\text { Quantidade em relação ao total de } \\
\text { combinações de negócios }\end{array}$ \\
\cline { 2 - 6 } Reconheceu Goodwill & 42 & 32 & 34 & $83,08 \%$ \\
\hline Reconheceu apenas Goodwill & 17 & 16 & 18 & $39,23 \%$ \\
\hline Não Reconheceu Goodwill & 8 & 2 & 8 & $13,85 \%$ \\
\hline Reconheceu apenas Intangível Identificável & 2 & 1 & 2 & $3,85 \%$ \\
\hline Não Reconheceu Intangível Identificável & 27 & 17 & 25 & $53,08 \%$ \\
\hline Reconheceu Goodwill e Intangível Identificável & 24 & 16 & 16 & $43,08 \%$ \\
\hline Reconheceu apenas Ganho por Compra Vantajosa & 3 & 0 & 1 & $3,08 \%$ \\
\hline $\begin{array}{l}\text { Reconheceu Ganho por Compra Vantajosa e } \\
\text { Intangível Identificável }\end{array}$ & 0 & 0 & 0 & $0,00 \%$ \\
\hline
\end{tabular}

Fonte: Elaborado pelos autores com base nos dados da pesquisa. 
Percebe-se na Tabela 1, considerando um total de 130 combinações de negócios analisadas no período entre 2012 e 2014, que foi reconhecido goodwill em 83,08\% das combinações de negócios identificadas, o que pode sugerir uma tendência das combinações de negócios brasileiras reconhecerem goodwill, enquanto que o ganho proveniente de compra vantajosa (deságio) foi reconhecido em apenas quatro combinações de negócios. Foram reconhecidos ativos intangíveis identificáveis e goodwill em 43,08\% das combinações de negócios observadas.

Outro ponto a destacar é que no período analisado, de um total de 130 combinações de negócios, 53,08\% não reconheceram intangíveis identificáveis na data da combinação de negócios, resultado que ao comparar com o percentual de reconhecimento do goodwill, percebese que as companhias tenderam a não reconhecer intangíveis identificáveis e atribuir a parcela a maior paga na transação ao goodwill, um ativo não passível de identificação individual.

Em 2012, duas companhias reconheceram apenas o intangível identificável. Em 2013, houve apenas uma companhia, que foi na aquisição da companhia Barcas S.A. pela CCR S.A., e em 2014 houve duas companhias, a Cemig S.A., que adquiriu a Retiro Baixo Energética S.A., e a Copel S.A. que adquiriu a São Bento Energia.

Dessa forma, pode-se inferir que o goodwill foi reconhecido em uma parcela significativa das combinações de negócios analisadas neste período, enquanto que o ganho por compra vantajosa foi pouco reconhecido nessas operações. Além disso, é possível afirmar que nem todas as combinações de negócios em que há reconhecimento do goodwill ocorre o reconhecimento de ativos intangíveis identificáveis. Na tabela 2 são apresentadas as denominações utilizadas pelas companhias para se referir ao ágio derivado da expectativa de rentabilidade futura ( goodwill).

Tabela 2: Denominação utilizada para o goodwill

\begin{tabular}{l|c|c|c|c}
\hline $\begin{array}{l}\text { Denominação utilizada } \\
\text { para goodwill }\end{array}$ & 2012 & 2013 & 2014 & $\begin{array}{l}\text { \% em relação ao total de } \\
\text { combinações de negócios } \\
\text { que reconheceram goodwill }\end{array}$ \\
\hline Ágio & 14 & 14 & 7 & $32,41 \%$ \\
\hline $\begin{array}{l}\text { Ágio por expectativa de } \\
\text { rentabilidade futura }\end{array}$ & 13 & 7 & 9 & $26,85 \%$ \\
\hline Ágio na aquisição & 1 & 0 & 3 & $3,70 \%$ \\
\hline Ágio apurado & 4 & 0 & 1 & $4,63 \%$ \\
\hline Ágio residual & 0 & 2 & 0 & $1,85 \%$ \\
\hline Ágio residual (goodwill) & 0 & 2 & 0 & $1,85 \%$ \\
\hline Ágio contábil (goodwill) & 1 & 0 & 0 & $0,93 \%$ \\
\hline Ágio (goodwill) & 2 & 5 & 3 & $9,26 \%$ \\
\hline Ágio pago (goodwill) & 2 & 0 & 0 & $1,85 \%$ \\
\hline Goodwill & 5 & 2 & 11 & $16,67 \%$ \\
\hline Total & 42 & 32 & 34 & $100 \%$ \\
\hline
\end{tabular}

Fonte: Elaborado pelos autores com base nos dados da pesquisa. 
Conforme a Tabela 2, das combinações de negócios em que houve reconhecimento do goodwill, 32,41\% aplicaram apenas o termo “Ágio" para se referir a este ativo, e 26,85\% denominaram o goodwill como Ágio por expectativa de rentabilidade futura ou expectativa de rentabilidade futura. O uso de somente a denominação "goodwill" foi encontrado em 16,67\% das combinações de negócios analisadas em que houve o reconhecimento deste ativo.

Referente aos fatores que integram o goodwill, a justificativa de expectativa de rentabilidade futura foi mencionada em $39,81 \%$ das combinações em que foi reconhecido goodwill, enquanto que $11,11 \%$ não apresentaram os fatores que integram o goodwill, a Tabela 3 demonstra esses resultados.

Tabela 3: Fatores que integram o goodwill

\begin{tabular}{l|c|c|c|c}
\hline Fatores que integram o goodwill & 2012 & 2013 & 2014 & $\begin{array}{c}\text { \% em relação ao total de } \\
\text { combinações de negócios } \\
\text { que reconheceram goodwill }\end{array}$ \\
\hline $\begin{array}{l}\text { Ágio por expectativa de rentabilidade } \\
\text { futura (ou benefícios econômicos futuros) }\end{array}$ & 17 & 15 & 11 & $39,81 \%$ \\
\hline $\begin{array}{l}\text { O excesso (ou diferença positiva) entre o } \\
\text { valor da contraprestação e o valor justo } \\
\text { dos ativos líquidos adquiridos }\end{array}$ & 10 & 6 & 16 & $29,63 \%$ \\
\hline $\begin{array}{l}\text { Lucratividade futura e às economias de } \\
\text { escala }\end{array}$ & 5 & 0 & 0 & $4,63 \%$ \\
\hline Sinergias esperadas & 7 & 1 & 2 & $9,26 \%$ \\
\hline Outros & 1 & 1 & 4 & $5,56 \%$ \\
\hline Não informou & 2 & 9 & 1 & $11,11 \%$ \\
\hline Total & 42 & 32 & 34 & $100,00 \%$ \\
\hline
\end{tabular}

Fonte: Elaborado pelos autores com base nos dados da pesquisa.

Considerando os fatores que integram o goodwill, é possível afirmar que na maioria das combinações em que houve reconhecimento do goodwill $(88,89 \%)$, foram mencionados fatores condizentes com os termos emanados pelo CPC 15 (R1), porém, conforme Souza (2015) reconhecer o goodwill considerando apenas uma expectativa de rentabilidade futura é subjetivo, pois não são conhecidos os fatores que justificam essa rentabilidade futura. Da mesma forma, resultados semelhantes já haviam sido constatados por Dahmash, Durand e Watson (2009), em que os autores concluíram que as informações relativas ao goodwill são divulgadas de uma maneira mais conservadora, apesar da sua relevância.

Vale mencionar que em relação ao goodwill, algumas companhias informaram como rentabilidade futura as sinergias ou as economias de escala esperadas em virtude da combinação realizada, todavia, não forneceram detalhamentos acerca dessas informações. A evidenciação desse item por estas companhias corrobora com o estudo de Henning, Lewis e Shaw (2000) no qual foi identificado que o item predominante existente no goodwill é a sinergia decorrente da combinação de negócios, o que sugere que as companhias tendem a associar o goodwill a sinergia. 
Na Tabela 4 é apresentada a estatística descritiva da proporção do goodwill reconhecido em relação à contraprestação. Para que não houvesse distorções no resultado, foi realizada a exclusão da companhia Profarma S.A. referente à aquisição da CSB Drogarias realizada em 2013, que reconheceu um goodwill 660,82\%. Tal exclusão também foi realizada no estudo de Souza (2015), pois também foi analisado o período de 2013. Em 2014 foi excluída a combinação de negócios realizada pela Algar S.A. que adquiriu a Rhealeza Volta Redonda Informática Ltda., reconhecendo um ágio correspondente a 327,53\% da contraprestação transferida.

Tabela 4: Proporção do goodwill em relação à contraprestação

\begin{tabular}{l|c|c|c|c}
\hline & 2012 & 2013 & 2014 & Média geral \\
\hline Média & $73,15 \%$ & $64,58 \%$ & $56,84 \%$ & $64,86 \%$ \\
\hline Erro padrão & $5,33 \%$ & $6,81 \%$ & $6,13 \%$ & $6,09 \%$ \\
\hline Mediana & $76,28 \%$ & $66,62 \%$ & $51,47 \%$ & $64,79 \%$ \\
\hline Desvio padrão & $34,53 \%$ & $37,92 \%$ & $32,41 \%$ & $34,95 \%$ \\
\hline Mínimo & $0,90 \%$ & $1,97 \%$ & $1,97 \%$ & $1,61 \%$ \\
\hline Máximo & $155,19 \%$ & $157,95 \%$ & $120,13 \%$ & $144,42 \%$ \\
\hline Quantidade de combinações & 42 & 31 & 28 & - \\
\hline
\end{tabular}

Fonte: Elaborado pelos autores com base nos dados da pesquisa.

Conforme a Tabela 4, é possível perceber que nos períodos analisados a média geral da proporção do goodwill em relação à contraprestação foi $64,86 \%$. Também é possível observar que a mediana nos três períodos analisados foi superior a $50 \%$, o que significa que mais da metade das combinações de negócios apresentaram um valor elevado da proporção do goodwill em relação à contraprestação. Referente aos valores máximos, percebe-se que nos três períodos a proporção do goodwill em relação à contraprestação foi superior a 100,00\%, apresentando uma média geral das proporções máximas de 144,42\%.

Dessa forma, pode-se afirmar que a proporção do goodwill em relação à contraprestação representa um valor considerável nas combinações de negócios. Quanto às informações referentes aos ativos intangíveis identificáveis, a Tabela 5 demonstra a evidenciação dos ativos intangíveis identificáveis.

Tabela 5: Informações sobre os ativos intangíveis identificáveis

\begin{tabular}{l|c|c|c|c}
\hline $\begin{array}{l}\text { Informações sobre os ativos } \\
\text { intangíveis identificáveis }\end{array}$ & 2012 & 2013 & 2014 & $\begin{array}{c}\text { \% em relação ao total de } \\
\text { combinações que reconheceram } \\
\text { ativos intangíveis identificáveis }\end{array}$ \\
\hline Informou a vida útil & 5 & 0 & 7 & $19,67 \%$ \\
\hline Informou o valor total & 11 & 8 & 12 & $50,82 \%$ \\
\hline Informou o valor individual & 26 & 15 & 17 & $95,08 \%$ \\
\hline Informou o nome individual & 26 & 15 & 17 & $95,08 \%$ \\
\hline
\end{tabular}

Percebe-se na Tabela 5, que das 61 combinações de negócios em que houve o reconhecimento dos ativos intangíveis identificáveis, apenas 19,67\% informou a vida útil, 
$50,82 \% \%$ informou o valor total e na maioria das combinações de negócios foi informado o valor individual e o nome individual dos ativos intangíveis identificáveis.

Dessa forma, é possível afirmar que são poucas as combinações de negócios em que é informada a vida útil dos ativos intangíveis identificáveis. Entretanto, a maior parte das combinações de negócios em que são reconhecidos ativos intangíveis identificáveis apresentam os valores individuais e os nomes dos ativos intangíveis identificáveis. A Tabela 6 apresenta quais os ativos intangíveis identificáveis reconhecidos nas combinações de negócios dos períodos analisados.

Tabela 6: Ativos intangíveis identificáveis reconhecidos

\begin{tabular}{l|c|c|c|c}
\hline $\begin{array}{l}\text { Ativos intangíveis } \\
\text { identificáveis reconhecidos }\end{array}$ & 2012 & 2013 & 2014 & $\begin{array}{c}\text { \% em relação ao total de combinações } \\
\text { de negócios que reconheceram ativos } \\
\text { intangíveis identificáveis }\end{array}$ \\
\hline Carteira de clientes & 12 & 2 & 11 & $40,98 \%$ \\
\hline Relacionamento de clientes & 7 & 7 & 1 & $24,59 \%$ \\
\hline Licença de operações & 2 & 2 & 1 & $8,20 \%$ \\
\hline Marcas & 14 & 6 & 10 & $49,18 \%$ \\
\hline Patentes & 0 & 1 & 0 & $1,64 \%$ \\
\hline Não competição & 12 & 3 & 3 & $29,51 \%$ \\
\hline Direito de uso de Software & 1 & 1 & 1 & $4,92 \%$ \\
\hline Fundo de comércio & 2 & 0 & 0 & $3,28 \%$ \\
\hline Direito de lavra & 3 & 0 & 0 & $4,92 \%$ \\
\hline Outros & 4 & 2 & 2 & $13,11 \%$ \\
\hline Total & 26 & 17 & 18 & $100,00 \%$ \\
\hline
\end{tabular}

Fonte: Elaborado pelos autores com base nos dados da pesquisa.

Dentre os ativos intangíveis identificáveis reconhecidos, o item "Marcas" foi reconhecido em 49,18\% das combinações de negócios que reconheceram ativos intangíveis identificáveis, em segundo foi "Carteira de clientes" com 40,98\% e acordos de "Não competição" com 29,51\%.

Sendo assim, pode-se afirmar que "Marcas", "Carteira de Clientes" e acordos de "Não competição" são os ativos reconhecidos na maioria das combinações de negócios observadas que reconheceram ativos intangíveis identificáveis. Quanto às informações referentes às combinações de negócios, a Tabela 7 apresenta o número de combinações de negócios em que foi informada a data de aquisição e o valor da contraprestação.

Tabela 7: Informações referentes às combinações de negócios

\begin{tabular}{l|c|c|c|c}
\hline $\begin{array}{l}\text { Informações referentes às } \\
\text { combinações de negócios }\end{array}$ & 2012 & 2013 & 2014 & $\begin{array}{c}\text { \% em relação ao total de } \\
\text { combinaçôes de negócios }\end{array}$ \\
\hline Informou o valor da contraprestação & 53 & 34 & 41 & $98,46 \%$ \\
\hline Informou a data de aquisição & 53 & 34 & 43 & $100,00 \%$ \\
\hline
\end{tabular}

Fonte: Elaborado pelos autores com base nos dados da pesquisa.

Na Tabela 7 é possível perceber que o valor da contraprestação e a data de aquisição, considerando que o CPC 15 (R1, 2011) exige que a data de aquisição do controle seja 
informada, foram evidenciados em quase todas as combinações de negócios observadas. $\mathrm{Na}$ Tabela 8 estão apresentadas as formas de pagamento das contraprestações realizadas pelas adquirentes.

Tabela 8: Forma de pagamento da contraprestação

\begin{tabular}{l|c|c|c|c}
\hline $\begin{array}{l}\text { Forma de pagamento da } \\
\text { contraprestação }\end{array}$ & 2012 & 2013 & 2014 & $\begin{array}{c}\text { \% em relação ao total de } \\
\text { combinações de negócios }\end{array}$ \\
\hline Em dinheiro & 27 & 24 & 22 & $56,15 \%$ \\
\hline Em ações & 4 & 1 & 5 & $7,69 \%$ \\
\hline Em dinheiro e emissão de ações & 8 & 6 & 6 & $15,38 \%$ \\
\hline Assunção de passivos & 0 & 1 & 0 & $0,77 \%$ \\
\hline $\begin{array}{l}\text { Em dinheiro e assunção de } \\
\text { passivos }\end{array}$ & 12 & 1 & 1 & $10,77 \%$ \\
\hline Não informou & 2 & 1 & 9 & $9,23 \%$ \\
\hline Total & 53 & 34 & 43 & $100,00 \%$ \\
\hline
\end{tabular}

Fonte: Elaborado pelos autores com base nos dados da pesquisa.

Percebe-se que dentre as formas de pagamento realizadas, $56,15 \%$ das combinações de negócios foram efetuadas com pagamento em dinheiro. A forma menos utilizada pelas companhias foi assunção de passivos, realizado apenas por uma companhia da amostra em análise, porém 10,77\% realizaram o pagamento por meio de dinheiro e assunção de passivos. Dessa forma, é possível afirmar que a maior parte das combinações de negócios analisadas foi realizada com o pagamento da contraprestação em dinheiro, o que demonstra que parece existir uma tendência ao reconhecimento maior de goodwill quando o pagamento é em dinheiro.

Quanto aos tipos de combinações de negócios, a Tabela 9 apresenta a quantidade de combinações de negócios de acordo com os tipos identificados.

Tabela 9: Tipos de combinações realizadas

\begin{tabular}{l|c|c|c|c}
\hline $\begin{array}{l}\text { Tipos de combinações } \\
\text { de negócios realizadas }\end{array}$ & 2012 & 2013 & 2014 & $\begin{array}{c}\text { \% em relação ao total de } \\
\text { combinaçôes de negócios }\end{array}$ \\
\hline Aquisição & 48 & 31 & 39 & $90,77 \%$ \\
\hline Fusão & 0 & 0 & 0 & $0,00 \%$ \\
\hline Incorporação & 5 & 3 & 4 & $9,23 \%$ \\
\hline Cisão & 0 & 0 & 0 & $0,00 \%$ \\
\hline Total & 53 & 34 & 43 & $100,00 \%$ \\
\hline
\end{tabular}

Fonte: Elaborado pelos autores com base nos dados da pesquisa.

Referente ao tipo de combinação de negócios realizado, a operação de aquisição foi realizada em 90,77\% das combinações de negócios analisadas. As incorporações identificadas correspondem a 9,23\% das combinações de negócios. Não foram identificadas operações de fusão e cisão, ressaltando que apenas integraram a amostra da presente pesquisa combinações de negócios em que houve transferência de controle. A Tabela 10 apresenta informações referentes às companhias observadas, como a rentabilidade do ativo, se negocia ADRs na NYSE e se foi mencionado o período de mensuração. 
Tabela 10: Rentabilidade, se negocia ADRs na NYSE e menção ao período de mensuração

\begin{tabular}{l|c|c|c|c|c}
\hline \multirow{2}{*}{$\begin{array}{l}\text { Rentabilidade das companhias e se } \\
\text { negocia ADRs na NYSE }\end{array}$} & Total & $\begin{array}{c}\text { Reconheceram } \\
\text { Goodwill }\end{array}$ & \multicolumn{2}{c}{$\begin{array}{c}\text { Não Reconheceram } \\
\text { Goodwill }\end{array}$} \\
\cline { 2 - 6 } & Companhias & Total & $\begin{array}{c}\text { Quantidade } \\
\text { Companhias }\end{array}$ & Total \\
\hline Rentabilidade inferior a 0 & 12 & 10 & $83,33 \%$ & 2 & $16,67 \%$ \\
\hline Rentabilidade entre 0 e 5 & 30 & 20 & $66,67 \%$ & 10 & $33,33 \%$ \\
\hline Rentabilidade entre 5,1 e 15 & 29 & 23 & $79,31 \%$ & 6 & $20,69 \%$ \\
\hline Rentabilidade acima de 15 & 5 & 3 & $60,00 \%$ & 2 & $40,00 \%$ \\
\hline Negocia ADRs na NYSE & 9 & 5 & $83,33 \%$ & 4 & $66,67 \%$ \\
\hline Mencionou o período de mensuração & 20 & 19 & $95,00 \%$ & 1 & $5,00 \%$ \\
\hline
\end{tabular}

Fonte: Elaborado pelos autores com base nos dados da pesquisa.

Não se percebeu uma tendência relativa ao nível de rentabilidade e reconhecimento do goodwill, visto que em todos os níveis observados, a maioria da amostra tendeu a reconhecer goodwill. Referente às companhias que negociam ADRs, a maior parte da amostra reconheceu goodwill, o que pode sugerir uma tendência de reconhecimento deste ativo por parte destas companhias nas combinações de negócios.

Quanto à menção ao período de mensuração, na amostra analisada apenas 20 companhias mencionaram o período de mensuração, conforme é possível observar na Tabela 10 e dentre estas companhias $95,00 \%$ reconheceram o goodwill. Talvez esse resultado tenha relação com o fato dos ajustes permitidos no período de mensuração serem em contrapartida do goodwill. Ainda a respeito do período de mensuração, ressalta-se que as companhias apenas utilizam o texto do CPC 15 (R1) sem especificar detalhes a respeito de possíveis alterações. A Tabela 11 apresenta a quantidade de companhias de acordo com o reconhecimento dos ativos intangíveis realizado nas combinações e o nível de governança em que estão classificadas.

Tabela 11: Reconhecimento dos ativos intangíveis e nível de governança

\begin{tabular}{l|c|c|c|c}
\hline \multicolumn{1}{c|}{ Características } & Tradicional & Nível I & Nível II & Novo Mercado \\
\hline Reconheceu Goodwill & 4 & 4 & 3 & 28 \\
\hline Não Reconheceu Goodwill & 4 & 1 & 0 & 7 \\
\hline Reconheceu apenas Intangível Identificável & 0 & 1 & 0 & 1 \\
\hline Não Reconheceu Intangível Identificável & 6 & 4 & 3 & 14 \\
\hline $\begin{array}{l}\text { Reconheceu Goodwill e Intangível } \\
\text { Identificável }\end{array}$ & 3 & 0 & 0 & 10 \\
\hline $\begin{array}{l}\text { Reconheceu apenas Ganho por Compra } \\
\text { Vantajosa }\end{array}$ & 0 & 0 & 0 & 4 \\
\hline $\begin{array}{l}\text { Reconheceu Ganho por Compra Vantajosa e } \\
\text { Intangível Identificável }\end{array}$ & 0 & 0 & 0 & 0 \\
\hline Total de companhias & 11 & 5 & 3 & 38 \\
\hline
\end{tabular}

Fonte: Elaborado pelos autores com base nos dados da pesquisa.

Conforme a Tabela 11, das companhias classificadas no Novo mercado, 73,68\% reconheceram goodwill, 36,84\% não reconheceram intangíveis identificáveis e 26,31\% reconheceram ativos intangíveis identificáveis e goodwill. Dentre as companhias sem 
classificação de nível de governança, 54,54\% não reconheceram intangíveis identificáveis e $36,36 \%$ reconheceram goodwill.

Das companhias classificadas nos níveis I e II, a maioria reconheceu goodwill. Sendo assim, percebe-se uma tendência que as companhias classificadas em algum nível de governança realizam o reconhecimento do goodwill em maior proporção do que as companhias sem nível de governança.

E por fim, quanto ao setor de atuação, a Tabela 12 apresenta o reconhecimento dos ativos intangíveis considerando o setor de atuação no qual as companhias estão inseridas.

Tabela 12 - Setor de atuação X reconhecimento de ativos intangíveis

\begin{tabular}{l|c|c|c|c}
\hline \multirow{2}{*}{ Setor de atuação } & \multicolumn{3}{|c}{ Reconhecimento dos ativos intangíveis } \\
\cline { 2 - 5 } & $\begin{array}{c}\text { Total de companhias } \\
\text { que realizaram } \\
\text { combinações }\end{array}$ & Goodwill & $\begin{array}{c}\text { Intangíveis } \\
\text { identificáveis }\end{array}$ & $\begin{array}{c}\text { Goodwill e } \\
\text { intangíveis } \\
\text { identificáveis }\end{array}$ \\
\hline Utilidade Pública & 9 & 2 & 5 & 0 \\
\hline Bens Industriais & 3 & 1 & 0 & 0 \\
\hline Construção e Transporte & 6 & 3 & 3 & 3 \\
\hline Consumo Cíclico & 12 & 10 & 2 & 7 \\
\hline Consumo não Cíclico & 10 & 10 & 3 & 5 \\
\hline Financeiro e Outros & 8 & 6 & 2 & 3 \\
\hline Materiais Básicos & 2 & 2 & 1 & 1 \\
\hline Não Classificados & 2 & 2 & 0 & 0 \\
\hline Tecnologia da Informação & 3 & 3 & 1 & 1 \\
\hline Telecomunicações & 2 & 1 & 1 & 1 \\
\hline
\end{tabular}

Fonte: Elaborado pelos autores com base nos dados da pesquisa.

Conforme a Tabela 12, percebe-se que a maior parte das companhias observadas estão concentradas nos setores de Consumo Cíclico, seguido do setor de Consumo não Cíclico e Utilidade pública. Das companhias classificadas no setor de Consumo Cíclico, 83,33\% reconheceram goodwil, e 16,67\% reconheceram intangível identificável. Referente às companhias do setor de Consumo não cíclico, 100\% reconheceram goodwil e 30\% reconheceram intangível.

\section{CONCLUSÕES}

Percebeu-se na amostra analisada que existe uma tendência ao reconhecimento de goodwill nas combinações de negócios, destacando que a maior parte das companhias não consegue no momento da transação identificar separadamente o intangível pelo qual ela está pagando a mais na combinação realizada. Estes resultados corroboram com os achados de Henning, Lewis e Shaw (2000); Dahmash, Durand e Watson (2009) e Souza (2015). 
No que concerne aos fatores que integram o goodwill, a maioria das companhias não apresentaram elementos que justificassem o reconhecimento do goodwill, apenas mencionaram que o goodwill foi gerado com base em uma expectativa de rentabilidade futura, ou que representa o excesso (ou diferença positiva) entre o valor da contraprestação e o valor justo dos ativos líquidos adquiridos. Dessa forma, percebe-se que há falta de divulgação por parte das companhias dos fatores que integram o goodwill reconhecido, o que contribui para sua subjetividade.

Quanto ao reconhecimento dos ativos intangíveis identificáveis, percebeu-se que os tipos "Marca", "Carteira de alunos" e acordos de "Não competição" são os ativos intangíveis identificáveis mais reconhecidos nas combinações de negócios analisadas. O estudo de Souza (2015) apresentou resultado semelhante a este.

No que compete à menção ao período de mensuração, apenas 20 companhias informaram o período de mensuração, sendo que a maior parte delas reconheceu goodwill. Sobre o setor de atuação, o setor de Consumo cíclico foi o que apresentou o maior número das companhias analisadas, representando $21,05 \%$ do total. Quanto ao nível de governança, percebeu-se que há uma tendência de as companhias que estão classificadas em algum nível de governança reconhecerem goodwill em maior proporção.

Nesse sentido, o presente estudo contribui para debates a respeito do reconhecimento dos ativos intangíveis identificáveis e do goodwill nas combinações de negócios, abordando principalmente suas características, os fatores que os integram, as denominações utilizadas para o goodwill e os tipos de ativos intangíveis identificáveis adquiridos.

Ressalta-se como limitações da presente pesquisa que os resultados encontrados dizem respeito à amostra e período analisado não podendo ser generalizados para outras companhias ou períodos diferentes. Como sugestão para pesquisas futuras sugere-se uma análise comparativa entre países acerca da evidenciação dos componentes do goodwill e intangíveis identificáveis reconhecidos nas combinações de negócios.

\section{REFERÊNCIAS}

BARROS, Thiago de Souza; RODRIGUES, Ana Maria Gomes. Concentração de atividades empresariais: uma análise das combinações de negócios e dos ativos intangíveis no Brasil. Revista de Gestão, Finanças e Contabilidade, v. 4, n. 2, p. 112-136, 2014.

CHAVES, Eduardo de Paula e Silva Chaves; JUNIOR e Tabajara Pimenta. Relação entre valor de mercado e ativo intangível na Bovespa. RAIMED - Revista de Administração IMED, 3(3), p. 239-251, 2013. 
COMITÊ de Pronunciamentos Contábeis. Pronunciamento Técnico CPC 04 R1, de 05 de novembro de 2010. Ativo Intangível. Disponível em: < http://www.cpc.org.br/CPC >. Acesso em: 27 de fevereiro de 2016.

Pronunciamento Técnico CPC 15 R1, de 03 de junho de 2011. Combinação de negócios. Disponível em: < http://www.cpc.org.br/CPC>. Acesso em: 07 de março de 2016.

COSTA, Giovanni Pacelli Carvalho Lustosa da; PAULO, Edson; BARBOSA, Glauber de Castro. Reconhecimento do Goodwill em Combinação de Negócios: Análise das Transações com Pagamento em Ações e em Dinheiro. Qualit@s Revista Eletrônica, v.12, n.2, 2011.

DAHMASH, Firas N.; DURAND, Robert B.; WATSON, John. The value relevance and reliability of reported goodwill and identifiable intangible assets. The British Accounting Review, v. 41, p. 120-137, 2009.

HENNING, Steven L; LEWIS, Barry L.; SHAW, Wayne H. Valuation of the components of purchased goodwill. Journal of Accounting Research, v. 38, n. 2, p. 375-386, 2000.

HENDRIKSEN, Eldon S; VAN BREDA, Michael F. Teoria da Contabilidade. 5. ed. São Paulo: Atlas, 2009.

HOSS, Osni, ROJO, Claudio Antonio, GRAPEGGIA, Mariana. Gestão de ativos intangíveis: da mensuração à competitividade por cenários. São Paulo: Atlas, 2010.

IUDÍCIBUS, Sérgio de; MARTINS, Eliseu; GELBCKE, Ernesto Rubens. Manual de Contabilidade das Sociedades por Ações. 7. ed. São Paulo, Atlas, 2007.

IUDÍCIBUS, Sérgio de. Teoria da Contabilidade. 5. ed. São Paulo, Atlas, 1997.

Teoria da Contabilidade. 11. ed. São Paulo, Atlas, 2015.

LANZANA, Ana Paula. Relação entre disclosure e governança corporativa das empresas brasileiras. 2004. P. 165. Dissertação de Mestrado - Faculdade de Economia, Administração e Contabilidade, Universidade de São Paulo, São Paulo.

MARION, José Carlos. Análise das demonstrações contábeis: contabilidade empresarial, 7. ed. Atlas, 2013.

MANTOVANI, Erick Fernandes Vieira; SANTOS, Fernando de Almeida. A contabilização do ativo intangível nas 522 empresas listadas na BM\&FBOVESPA. Revista de Administração e Inovação, v.11, n.3, p.311-328, 2014.

MARQUES, José Augusto Veiga da Costa; SANTOS, Ronaldo Francisco dos; GOUVEIA, Verônica Andréa Lima.

MARTINS, Eliseu, GELBCKE, Ernesto Rubens, SANTOS, Ariovaldo dos, IUDÍCUBUS, Sérgio de. Manual de contabilidade societária: aplicável a todas as sociedades de acordo com as normas internacionais e do CPC. 2. ed. São Paulo, Atlas, 2013.

NAKAYAMA, Wilson Kazumi; SALOTTI, Bruno Meirelles. Fatores determinantes do nível de divulgação de informações sobre combinações de negócios com a entrada em vigor do pronunciamento técnico CPC 15. Revista de Contabilidade \& Finanças, v.25, n. 66, p. $267-$ $280,2014$.

NEVES, Silvério das. Contabilidade avançada e análises das demonstrações financeiras. 16. ed. Saraiva, 2011.

RICHARDSON, Roberto Jarry. Pesquisa social: métodos e técnicas. 3. ed. São Paulo, Atlas, 1999. 
SOUZA, Maíra Melo. Value relevance do nível de disclosure das combinações de negócios e do goodwill reconhecido nas empresas brasileiras. 2015. 183p. Tese (Doutorado) Universidade Federal de Santa Catarina. Programa de Pós-Graduação em Administração, Florianópolis, 2015.

SCHMIDT, Paulo, SANTOS, José dos. Avaliação de ativos intangíveis. 2. ed. Atlas, 2009.

SCHMIDT, Paulo, SANTOS, José dos, FERNANDES, Alves. Contabilidade avançada: aspectos societários e tributários. 3. ed. Atlas, 2012.

TEIXEIRA, Juliana Pauli, PETRI, Sergio Murilo, MARQUES, Tatiane de Oliveira. O valor da marca como um ativo intangível: um estudo de caso da Weg S.A.. Revista de Contabilidade do Mestrado em Ciências Contábeis da UERJ (online), v. 17, n.2, p. 45 - p. 67, 2012.

WATANABE, Sérgio, FERREIRA; Marcio Martins, JÚNIOR; Nilson Gianoto, SZUSTER, Natan. Evidenciação contábil comparativa entre Brasil e EUA das práticas contábeis realizadas na operação de combinação de negócios em uma empresa do setor de papel e celulose. Pensar Contábil, v.8, n.34, v. p. 01-16, 2006. 